HUOM! Tämä on alkuperäisen artikkelin rinnakkaistallenne. Rinnakkaistallenne saattaa erota alkuperäisestä sivutukseltaan ja painoasultaan.

Käytä viittauksessa alkuperäistä lähdettä:

Bastiaansen, M., Lub, X.D., Mitas, O., Jung, T.H., Ascenção, M.P., Han, D.-I., Moilanen, T., Smit, B. and Strijbosch, W. (2019), "Emotions as core building blocks of an experience", International Journal of Contemporary Hospitality Management, Vol. 31 No. 2, pp. 651-668.

https://doi.org/10.1108/IJCHM-11-2017-0761

PLEASE NOTE! This in an electronic self-archived accepted version of the original article. This reprint may differ from the original in pagination and typographic detail.

Please cite the original version:

Bastiaansen, M., Lub, X.D., Mitas, O., Jung, T.H., Ascenção, M.P., Han, D.-I., Moilanen, T., Smit, B. and Strijbosch, W. (2019), "Emotions as core building blocks of an experience", International Journal of Contemporary Hospitality Management, Vol. 31 No. 2, pp. 651-668.

https://doi.org/10.1108/IJCHM-11-2017-0761

(C) 2019 Emerald Publishing Limited 


\title{
Emotions as core building blocks of an experience
}

\begin{abstract}
Purpose

To stimulate the discussion in the fields of hospitality, tourism, and leisure on what exactly constitutes "an experience" and how to measure it, we unpack the experience construct into its core constituent elements, namely, emotions.
\end{abstract}

\section{Approach}

The paper reviews insights from psychology and cognitive neuroscience that define experiences as a fine-grained temporal succession of emotions that occur during an experiential episode. Limitations of current methods for measuring experiences are discussed, after which biometric and neuroscientific methods are reviewed that are optimally geared toward measuring emotions as they occur during an experience with fine temporal detail.

\section{Findings}

An overview is presented of the available studies within the fields of hospitality, tourism, and leisure that use these methodologies. These studies show that using these methodologies provides a fruitful methodological approach to measuring experiences in real time.

\section{Practical implications}

Companies are constantly seeking to create memorable experiences for their customers. The proposed research methodologies allow companies to get a more fine-grained image of what impacts customers over the course of their experience and to actively integrate the use of emotions into creating experiences, as emotions are key to making them memorable.

\section{Originality/value}

The paper sketches the contours of a rapidly emerging framework that unpacks memorable experiences into their constituent element - emotions. It is proposed that this will contribute to a deeper understanding of how consumers experience offerings in the hospitality, tourism, and leisure industry.

\section{Keywords}

Experience design, experience research, emotions, research methods, biometric methods, neuroscientific methods

\section{Article classification}

Conceptual paper 


\section{Introduction}

Statics, the physicist knows, is only an abstraction from dynamics. Dynamics, on the other hand, deals with the general case and might be described as the theory of how and why something does happen. Thus, only dynamics can give us the real, universally valid laws of mechanics; for nature is process; it moves, changes, develops. (Popper, 1957, pp. 39-40)

In the past two decades, experiences have been a central construct for both scholars and professionals in hospitality, tourism, and leisure (Pine \& Gilmore, 1998, 2011). Intuitively, everyone knows what an experience is. Yet remarkably little academic debate or conceptual clarity about what exactly constitutes an experience and how it develops within individuals over time exists, even though the psychological literature has much to offer in this respect. Theoretical efforts within hospitality, tourism, and leisure have mainly aimed at listing a widely varying number of experience dimensions, which are heavily dependent on specific settings and contexts. As a result, there is little consensus about how to delineate the experience construct and even less on how to measure it.

What is lacking is the development of an overarching, central theory of experience in our field. However, a long tradition in experimental psychology and cognitive neuroscience in thinking about experiences does exist (Jantzen, 2013). In this paper, we take those insights as a point of departure and propose that emotions form the key ingredient of an experience. More precisely, it has been convincingly demonstrated that it is the succession of instantaneous emotional responses during an experience (occurring in the subsecond range) that determines how it is evaluated and remembered (Kahneman, 2011). Moreover, experience varies greatly within individuals, so we should understand experience as a withinperson, predominantly emotional, dynamic process that develops over time. A measure for experience should therefore ideally be able to track emotions continuously over time. However, current research methodologies based on postexperience self-reports fail to capture these temporal dynamics appropriately.

In the present paper, we aim to stimulate the discussion within our field on what exactly constitutes "an experience," by sketching the contours of a theoretical and quantitative methodological framework that unpacks experience into its constituent elements, with a strong emphasis on emotions as the core building blocks of experiences. Moreover, we present an overview of state-of-the-art quantitative (physiological and psychometric) methodologies that are optimally geared toward providing continuous measures of emotions during an experience.

\section{Unpacking the experience construct}

\section{Experience as a central construct in hospitality, tourism, and leisure}

Experiences have emerged as a central construct in psychological research in the 1960s, for instance, in the work of Csikszentmihalyi (1990) on the psychology of optimal experiences and Maslow (1964) on peak experiences. According to Maslow, peak experiences are short in duration and accompanied by intense positive emotions and feelings of affection, leading to a person transcending ordinary reality, losing track of time and place. With their research, Maslow and Csikszentmihalyi opened up the experience construct for research beyond religious contexts. In hospitality, tourism, and leisure (for a review, see e.g. Ritchie et al., 2011), experiences have been researched in terms of sought experiences (e.g., in mountain climbing; Beedie \& Hudson, 2003; Tsaur et al., 2013) and unexpected experiences (in wilderness, cultural activities and gastronomy; Sims, 2009; Tan et al., 2013). 
Pine and Gilmore (1998) defined experiences as an economic offering. According to these authors, "Commodities are fungible, goods tangible, services intangible, and experiences memorable" (Pine \& Gilmore, 1998, p. 98). In their perspective, next to transformations, experiences are considered to be the highest level of economic offering and add substantial economic value. As such, they propose that we have been moving from a service economy to an experience economy. For hospitality, tourism, and leisure, experiences certainly are the core business, and as such, experiences have become central to a substantial amount of scientific research in this field. In this regard, it is of crucial importance to be able to accurately measure experiences offered across industries. Measuring experiences precisely might be difficult, but better ways of doing so are desperately needed by experience industry managers. The well-known strategic business management quote, "You can't manage what you don't measure", commonly attributed to management guru Peter Drucker (McAfee \& Brynjolfsson, 2012), illustrates that without practical ways of measuring the effects of their experiences, managers are ill-equipped for knowing whether their efforts are generating improvement. Therefore, measuring experiences is essential. However, to be able to measure experiences with sufficient reliability and validity, one needs to be very precise about what exactly constitutes a memorable experience. As we explain in the following paragraphs, experiences are only memorable and meaningful when they evoke emotions.

\section{Experiential episodes}

To get a better grip on the experience construct, one should begin by noting that there is agreement in the psychological literature that our stream of consciousness is being divided into episodes (Tulving, 1989; Baddeley, 2000), through the activation of mental models (Brewer, 1987), schemata (Howard, 1987), or knowledge stored in episodic memory (Berntsen \& Rubin, 2012). For the sake of clarity, we will refer to such episodes here as experiential episodes. Note that experiential episodes can occur on different time scales, ranging from seconds/minutes to several weeks, a phenomenon that has been termed duration neglect (Fredrickson \& Kahneman, 1993). For example, the first interaction with a concierge (a few seconds), dinner at a Michelin-starred restaurant (a few hours), a visit to a theme park (a day), a stay at a hotel (a long weekend), or a summer holiday (several weeks) are all considered experiential episodes. Episodes occurring at longer time scales (so-called extended experiences; Arnould \& Price, 1993) are obviously not related to a single event or activity; rather, they are considered a temporally extended series of events and activities that together form the narrative of an episodic memory trace, with specific emotions being linked to it (Berntsen \& Rubin, 2012).

\section{Experiential episodes vs remembered experiences}

Second, it is important to realize that not everything in our lived experience, or stream of consciousness, is memorable. The daily routine of, say, driving home after work is just one example of an experiential episode that, oftentimes, is not a memorable experience, unless for some reason it stands out from the daily routine (such as seeing right before you a beautiful deer cross the road or witnessing a terrible accident happen). The distinction between experiential episodes and remembered experiences has a long history in the psychological literature and goes all the way back to William James (James, 1912). It is not our intention to provide a detailed review of this literature, as excellent reviews are available elsewhere (Kahneman \& Riis, 2005; Kahneman, 2011; Jantzen, 2013). Instead, we focus here on the implications that the distinction between experiential episodes and remembered experience have for conceptualization and methodology of research in the fields of leisure, tourism, and hospitality. More specifically, this distinction raises the question of precisely when and how an experiential episode translates into a memorable experience. In other words, what are the 
essential building blocks of a memorable experience? The management implications of the bridge between experiencing and (memorable) experiences give this question urgency, as often memorable experiences predict future revisit or recommendation decisions (Zajchowski et al., 2017).

\section{Emotions are the main building blocks of memorable experiences}

As reviewed by Scott and Le (2017), in addition to the physical context - the stage at which an experience takes place - a number of prime candidate constituents of experiences have been identified: Attention directs our mental resources to stimuli that are perceived as being salient; involvement refers to a person's level of interest and personal relevance in relation to the staged offerings at a site or destination; engagement is a complex construct involving multiple mental processes, all related to the feeling of being 'in the moment'; immersion is the sensation of being surrounded by a completely other reality and is most prominently studied in the context of gaming and virtual reality (Ermi \& Mäyrä, 2005). Finally, there is the related notion of cognitive absorption, conceptually close to flow (Csikszentmihalyi, 1990), in which five dimensions are distinguished: temporal dissociation, attentional focus, increased enjoyment, control, and curiosity. In an even broader conceptualization of experiential episodes, Pearce and Zare (2017) identify sensory, cognitive, affective, behavioral, and interpersonal elements of the experience in what they term the 'orchestra model' of experience.

In this paper, we focus predominantly on the affective element, notably the role of emotions in experience. We argue that emotions are a core component of experiences, as emotions make experiences memorable. At the same time, emotions are much neglected in the current hospitality, tourism, and leisure literature (Moyle et al., 2017), although recently there has been a rapidly increasing awareness of the importance of emotions for understanding memorable experiences in this field (Li et al., 2015; Moyle et al., 2017; Skavronskaya et al., 2017)/

Emotions are biologically-based responses to situations that are seen as personally relevant and constitute the main driving force of human behavior (Ekman, 1992). Emotions are expressed at three levels: subjective experience (that is, how people 'feel' them); expressive behavior (how people act them out); and physiology (the bodily changes that accompany emotions, such as increased heart rate and blood pressure, and hormonal changes, amongst others).

A substantial amount of research has been devoted to establishing the relationship between experiencing and remembering (Fredrickson, 2000; Kahneman, 2011; Conner \& Barrett, 2012; Zajchowski et al., 2017). The overall approach used in most of the existing studies is to relate postexperience self-reports to in-the-moment self-reports (termed 'experience sampling'; Hektner et al., 2007), ambulatory assessment (Fahrenberg \& Myrtek, 1996), or ecological momentary assessment (Stone \& Shiffman, 1994), depending on the exact field of study. The general picture that emerges out of the existing studies is that the emotions that are present during the experiential episode determine how it is being evaluated or remembered.

More specifically, the peak positive or negative emotions during the experiential episode and the emotional state at the end of it (the so-called peak-end rule; Kahneman et al., 1993; Fredrickson, 2000) play a crucial role in the global evaluation and memorability (or episodic recollection) of an experiential episode that seems to be shaped by the emotions at selected moments during the experience. These conclusions are in line with the neuroscientific observation that emotions promote both the encoding and the retrieval of information from episodic memory (LaBar \& Cabeza, 2006) and with the psychological observation that (autobiographical) episodic memory is often not very precise, with the 
omission of certain aspects, and with an overemphasis on other aspects of the experiential episode (Berntsen \& Rubin, 2012).

In sum, the current understanding from various scientific disciplines is that in order to capture the memorability of an experiential episode, one needs to focus on the emotional processes that occur within a person over time as the experiential episode unfolds. This is of crucial importance, since the memorability of an experiential episode is essential in guiding global evaluations of the experience and future decisions about repeat visit and recommendation behavior (Kahneman, 2011). To wrap up, the conceptual model of the experience construct that we propose is given in Figure 1.

$$
\text { *** Insert Figure } 1 \text { here *** }
$$

\section{Current quantitative approaches to measuring experiences}

Both qualitative and quantitative methods have been used in previous studies in an attempt to understand and measure experiences. Even though previous studies have focused on various aspects of the experience, all have acknowledged the importance of investigating not only the customer's internal factors (such as emotions, thoughts, and evaluations triggered by experiences) but also external variables (such as the physical environment, employees, and other customers), which seem to have a significant impact on the overall experience and the evaluation of the experience (Falk \& Dierking, 2016). In this section, we briefly describe the main quantitative approaches that have been followed to measure (memorable) experiences in leisure, tourism, and hospitality. It should be emphasized that our brief discussion of experience measurement techniques is limited to quantitative approaches. Although excellent qualitative research methods have been used to measure experience (see, for example, Chang \& Horng, 2010; Trischler \& Zehrer, 2012), discussing these approaches in sufficient depth is beyond the scope of this paper. Also, we do not provide a comprehensive review of the quantitative literature. Rather, we address the main quantitative methodological approaches that have been followed and illustrate these with a few examples.

Within the various approaches to measuring experiences, questionnaires are still the most widely used research instrument, as they are comparatively easy to develop and adopt. A number of studies have developed measurement scales of hospitality, tourism, and leisure experiences based on Pine and Gilmore's (1998) experience realms model (e.g., Oh et al., 2007; Park et al., 2010; Mehmetoglu \& Engen, 2011; Kim et al., 2012). However, while Mehmetoglu and Engen (2011) suggest that a basic evaluation of the experience could be attempted by means of investigating feeling, learning, being, and doing, surveys only access a respondent's cognitive evaluations of feeling, learning, being, and doing.

At the same time, the notion that emotions play a crucial role in shaping an experience has led other researchers to focus on emotions as the relevant experiential variable to measure. This research includes several cross-sectional studies (Nawijn et al., 2013; Nawijn \& Fricke, 2015; Gillet et al., 2016; Konijn et al., 2016) and a handful of longitudinal studies based on daily diary data (Coghlan \& Pearce, 2010; Mitas et al., 2012; Nawijn et al., 2013; Lin et al., 2014). Using questionnaires to measure constructs, a number of studies have employed a multidimensional approach, adding other cognitive and behavioral measurements (Mumm \& Mutlu, 2011; Van Schaik \& Ling, 2012).

Several commonly used emotion scales exist for this type of research. Given that hospitality, tourism, and leisure experiences are often rich with positive emotions, the modified Differential Emotions Scale (Cohn et al., 2009), which focuses on a breadth of positive emotions at various levels of arousal, is often recommended by researchers in our field. It overlaps substantially with the Destination Emotions Scale (Hosany et al., 2015) and addresses the lack of diversity in positive emotions in the original Differential Emotions Scale 
as well as in PANAS and other commonly used scales in social psychology. The Geneva Emotion Wheel (Scherer, 2005) uses 20 categories of emotions for evaluation. Richins' Consumption Emotions Set (Richins, 1997) uses word triplets in an attempt to enrich participants' recognition of emotions compared to the above scales that use a single emotion word per item. Finally, in contrast to verbal scales, the pictorial approach of using so-called self-assessment manikins (Bradley \& Lang, 1994) is able to provide a quick assessment of the participant's feeling using schematic manikins and may allow access to more than just cognitive evaluations of the event.

\section{Validity issues in experience measurement}

As said, the large majority of studies that attempt to measure experiences in the field of hospitality, tourism, and leisure have made use of self-reports, be it via postexperience selfreports (questionnaires and interviews) or in-the-moment self-reports (experience sampling and related methodologies). We are convinced of the usefulness of self-report methodology for measuring complex, predominantly cognitive components of the experience construct (such as attention, involvement, engagement and immersion). However, having established that the ebb and flow of emotions during an experiential episode provides crucial ingredients for transforming the episode into a memorable experience, one may question whether relying exclusively on these traditional research techniques constitutes the optimal research methodology for measuring the emotions that create memorable experiences. Research methods that are based on self-reports inherently fail to fully capture the essential emotional dynamics of experiences in a sufficiently valid manner, for at least four reasons (Larsen \& Fredrickson, 1999).

First, by definition, postexperience self-reports measure an experience after the experiential episode has ended. They therefore measure the memory of the experiential episode-however recent-rather than the experience itself (Zajchowski et al., 2017), which may have adverse effects on reliability, as experiences might be remembered differently over time (Tonetto \& Desmet, 2016). In addition, a postexperience self-report is subject to aggregation processes; respondents in some non-transparent manner have to combine their multiple and often varied momentary emotions into one overall report. Attempts to overcome these obvious limitations on validity, by using in-the-moment self-report techniques such as experience sampling, face the inherent problem that the process of measuring interferes with the process to be measured. Experience sampling requires people to momentarily step out of the experience, reflect upon it, answer questions, and then step back into the experience. As such, experience sampling and related techniques are invasive tools for measuring experiences and seem to be especially inappropriate if the experiential episode has a short time scale (such as a ride on a roller coaster) or if the experience is immersive (such as being in a Virtual Reality [VR] environment, having an intimate dinner, or attending a classical music concert). Second, self-reports force people to enter into an evaluative, cognitive appraisal mode. At best, the data one obtains are a valid reflection of the cognitive appraisal of (a series of) emotions, which is not the same as measuring the emotional response itself. Many theories exist on the relationship between emotional processes and cognitive processes (for a review, see Forgas, 2008), and they all agree that it is hardly possible to obtain an objective and valid cognitive appraisal of a series of emotions. Third, self-reports are subject to considerable bias resulting from social desirability and emotional coping strategies (e.g., repression of negative emotions; Larsen \& Fredrickson, 1999). Fourth, although a substantial part of our emotions is consciously accessible, another and equally substantial part of it is unconscious in nature (Clore \& Ketelaar, 1997; Öhman, 1999; LeDoux, 2000; Winkielman \& Berridge, 2004). Therefore, self-reports, which rely on conscious awareness, necessarily only 
capture the cognitive appraisal of a subset of the emotions that make up the experiential episode.

In sum, we argue that experience measurement that is based exclusively on self-reports faces inherent validity issues, as it fails to capture the temporal dynamics of the succession of positive and negative emotions that characterizes the experiential episode. In our view, this has at least three negative consequences. First, the lack of a continuous temporal measure of emotions restrains experience design managers in optimizing experiences (for instance, seeking the optimal peak and end composition of the episode, or detecting less interesting or even detrimental parts of it). Second, it prevents researchers from further specifying principles of good experience design, such as further refining the peak-end hypothesis or challenging it, for that matter). And third, self-reports do not validly capture the core component of an experience, which makes it memorable: emotions. Therefore, both hospitality and tourism industry managers and researchers would benefit from an additional set of research methodologies, which together with the current approaches make for a more comprehensive and effective toolbox for measuring experiences. In the next section, we list a number of possibilities for expanding the experience researcher's toolbox in this direction.

\section{Measuring emotions during an experience - a methodological framework and some empirical data}

To overcome the validity issues of current approaches to measuring emotions during experiential episodes delineated in the previous section, we propose studying experiences with research methods borrowed from psychology and neuroscience, which are better geared for the task of capturing the successive emotions that shape the memorability of an experience. We see the bodily expression of emotional responses - as measured through recordings of brain activity (electroencephalography, or EEG) and through biometric measures such as facial expression, heart rate, and skin conductance - as prime candidates for better understanding the intricate relationship between emotions and experiences (Larsen \& Fredrickson, 1999). Here, we present a very brief overview of the rationales behind the different methodologies we propose. In addition, we review some of the efforts that have been undertaken in the field of leisure, tourism, and hospitality to employ these methodologies for experience research. The available empirical data shares the perspective of aiming to bridge the gap between emotional responses, on the one hand, and experiences, on the other hand.

\section{Decoding emotions from facial expressions}

Pioneered by Paul Ekman and his Facial Action Coding System (FACS; Ekman \& Friesen, 1978), deriving information about emotions from observations, photographs, and videos of facial expressions dates back to the 1960s. FACS is based on the notion that the face is rich in emotional expression. Hence, studying the activity of the muscles underneath the surface of the face informs us of the presence of emotions. Each possible contraction or combination of movements is encoded as one of 28 action units, with additional action units describing movements of the head, eyes, and gross behavior patterns such as biting one's lip or speaking. This approach has been widely used and appreciated by academic researchers in psychology (Ekman, 1993; Cohn et al., 2007).

Recent innovations in software have rendered this subfield of emotion research accessible by making it possible to import photo or video recordings onto a computer, which then captures frame-by-frame action unit coding without the need for extensive expert input. This technology places facial coding within the reach of typical hospitality, tourism, and leisure organizations. Available software packages include the Affectiva Affdex development kit (McDuff et al., 2016) and Noldus FaceReader (Lewinski et al., 2014). However, to the best 
of our knowledge, facial coding has not yet been applied in hospitality, tourism, and leisure research.

\section{Physiological measures of emotions}

Moving beyond what is observable to the naked eye, fundamental psychophysiological research on physiological correlates of emotional experiences (Bradley \& Lang, 2000; Lench et al., 2011) has demonstrated that certain physiological measures are especially sensitive to emotions. This makes these measures very useful for studying the succession of emotions that occur while an experiential episode is unfolding over time. Here, we discuss three common and well-established physiological markers of emotions: facial electromyography (EMG), the skin conductance response, and heart rate variability.

Facial EMG entails recording the electrical activity (EMG) of facial muscles, which is a more invasive yet more sensitive way of decoding facial expressions than the approach described in the previous paragraph.

A skin conductance response (SCR), also termed electrodermal activity (EDA) or galvanic skin response (GSR) refers to changes (increases) in the skin's ability to conduct electricity caused by an opening of the sweat glands. These sweat glands are controlled by the sympathetic nervous system, which is activated by emotional arousal. Hence, SCRs are considered to be a reliable index of emotional arousal (Bradley et al., 2008).

High-frequency heart rate variability (HRV), corresponding to the rate of firing of the vagus nerve, relates to individuals' ability to return the body to a low-arousal state after an emotional stimulus (Appelhans \& Luecken, 2006), and can therefore also be used as a proxy for emotional arousal. The two measures combined provide a good view on emotional engagement and, under certain circumstances in a controlled laboratory setting, can even distinguish to a limited extent between some basic emotions (Ekman et al., 1983; Lang et al., 1993).

A limitation of much existing research on physiological expression of emotional engagement is its ecological validity. Almost all of the cited studies emphasize experimental and contextual control, thus studying emotions as induced in the lab using episodic recall or carefully controlled sensory stimulation. Such research designs put participants through rather different experiences than a visit to an amusement park, hotel room, or heritage site. However, as wearable recording equipment becomes increasingly available, physiological measurements are increasingly being used in more ecologically valid settings.

Researchers in our field are beginning to see the potential in using physiological signals to measure the emotional component of experiences. In a lab setting, Li et al. $(2016,2017)$ used facial EMG and SCR to measure emotional responses while study participants watched tourism destination advertisements. The researchers observed that physiological measures show reliable emotions that are consistent with post hoc interviews (Li et al., 2016) and further observed that the physiological effects of watching advertisements were weaker than self-reports of emotion, which suggests that self-reports may overestimate emotional responses (Li et al., 2017). Studies outside of the lab, in ecologically valid settings, are increasingly being reported. Kim and Fesenmaier (2015) measured the SCR of two heritage tour participants in the city of Philadelphia and linked a descriptive qualitative analysis of these data to their verbal descriptions of the experience. Further, Li et al. (2012) studied HRV along with self-reports of emotions while tourists were interacting with macaques in a Chinese natural park and found both indicators to reveal positive responses to these interactions. In the field of leisure, In a large-scale study on museum visitors (Tschacher et al., 2012), Tröndle and colleagues continuously measured HRV and SCR in more than 500 visitors whose exact location was tracked, enabling the researchers to make 'emotion maps' of the museum floorplan (Tröndle et al., 2014a) to identify emotional responses to individual 
artworks (Tröndle \& Tschacher, 2012), establish different emotional response patterns between men and women (Tröndle et al., 2014b), and identify different visitor types (Kirchberg \& Tröndle, 2015), amongst others. Together, these studies confirm the usefulness of physiological measures as a new tool to capture emotions during hospitality, tourism, and leisure experiences in situ.

\section{Measuring from the brain - neural correlates of emotions}

An intriguing possibility to study emotional responses that arise during an experiential episode is the recording of the neurophysiological responses (i.e., brain activity) associated with emotions, since different emotions are thought to be associated with distinct physiological patterns (Ekman, 1992).

Emotional brain responses have been measured predominantly by two neuroimaging methods: functional magnetic resonance imaging (fMRI; Cabeza \& Nyberg, 2000; ENREF 15 Phan et al., 2002) and electroencephalography (EEG; Olofsson et al., 2008; Hajcak et al., 2012). There is a large body of evidence on which aspects of fMRI and EEG signals are indicative of emotional engagement. In this work, we focus solely on EEG as a neuroimaging method, because (1) fMRI research is prohibitively expensive for experience measurement research projects in the hospitality, tourism, and leisure industries, and (2) fMRI research imposes so many constraints on research participants (e.g., lying still in a scanner, not moving) that it is difficult to see how one can arrive at acceptable levels of ecological validity in experience research.

EEG signals are based on the fact that brain activity operates by minute changes in electrical potential that travel from one nerve cell to another across the networks of the brain. The raw, untreated EEG signals are not very informative with respect to specific cognitive or emotional processes in the brain. However, after well-established signal-processing techniques are applied, the recorded signals can be reliably and validly related to emotional responses, by studying either EEG oscillations (Harmon-Jones et al., 2010; Bastiaansen et al., 2012) or the more widely used, so-called event-related potentials (ERPs; see Luck, 2014 for an accessible introduction to ERP data analysis and ERP research). Below, we briefly discuss both approaches and review some of the work applying them.

\section{EEG oscillations and emotional engagement}

EEG recordings are characterized by a superposition of oscillations at different frequencies. Thorough analysis of oscillations at different frequencies (or better, in different frequency bands) has shown that some of these oscillations are carried by specific networks in the brain (Varela et al., 2001; Buszáki \& Draguhn, 2004; Mantini et al., 2007) and that there is some degree of functional specialization for different frequencies (Bastiaansen et al., 2012). Specifically, oscillations in the $10-\mathrm{Hz}$ frequency band, usually referred to as alpha activity, have been shown to be larger over the left frontal part of the brain following positive emotions and over right frontal areas as a result of experiencing negative emotions (HarmonJones et al., 2010). Therefore, the asymmetry of these frontal alpha oscillations can be used as a real-time index of the succession of positive and negative emotions during an experiential episode.

Ongoing work in one of our research groups is seeking to validate the use of frontal alpha asymmetry in experience research. In this project, short VR movies (of durations ranging from 3 to 14 minutes), delivered through Samsung VR Gear equipment, were used to engage research participants in an immersive experience. Concurrently, EEG was measured from 32 locations on the scalp. After the initial viewing of the VR movie, participants who were asked to retell what they had just experienced, were subsequently prompted to segment their story into different parts, and to give one rating per segment on its emotional valence 
(following the procedure described by Bradley \& Lang, 1994). This yielded a sequence of valence ratings that covered the entire episode of the VR movie. Preliminary analyses show significant correlations between valence ratings and alpha power over frontal brain areas. These findings validate EEG as a tool to study, with subsecond resolution, the succession of positive and negative emotions during an experiential episode, which bypasses the use of selfreports.

\section{Event-Related Potentials (ERPs) as an index for emotions}

Another approach to using EEG in experience research is to follow an analysis strategy that uses repeated presentations of stimuli (say, pictures), which induce reliable changes in the EEG. When the EEG is averaged over a number of repeated presentations of pictures from a certain category, the "signal", which is the part of the EEG that is related to the processing of those pictures (called "events", hence the term event-related potential, or ERP) can be separated from "noise", that is, the brain activity that is not related to processing these photos (the ongoing overall EEG signal). Typically, a number (20-40) of stimuli from one and the same category need to be presented for the ERP signal to properly emerge from the noise (Luck, 2014). ERP waveforms are characterized by a succession of peaks and troughs (called ERP components) that reflect the emotional and cognitive brain activity elicited by the stimuli (Luck \& Kappenman, 2011). Five decades of active ERP research have characterized in detail which ERP components are sensitive to emotional processing (Olofsson et al., 2008; Hajcak et al., 2012).

In two studies, the effects of destination marketing stimuli (e.g., TV commercials, movies prominently featuring a tourism destination) on participants' affective destination image (Baloglu \& McCleary, 1999; San Martín \& Del Bosque, 2008) were assessed by quantifying changes in emotional responses elicited by pictures of the destination with ERPs (Bastiaansen et al., 2015; Bastiaansen et al., 2018). In both studies, increased emotion-related ERP components were observed after, as compared to before, viewing marketing stimuli, which indicates that the marketing stimuli were effective in coupling a positive emotion to the destination, and thus in improving destination image.

As with facial decoding and physiological measures, using EEG also has a few obvious limitations in its applicability to experience research. Although technically it is possible to measure EEG outside of the laboratory using ambulatory EEG equipment (Matthews et al., 2008; Yazicioglu et al., 2008), in practice it is hardly possible to obtain recordings of sufficient quality when participants are freely moving, as movement introduces massive measurement error (Mihajlović et al., 2015). This imposes considerable constraints on the type of experiences that can be studied-it is at present certainly not possible to study experiences such as a theme park visit, a checkout at a hotel, or a ride on a roller coaster with EEG in a straightforward manner. However, a viable alternative to these real-life experiences is to make use of the rapidly emerging VR technology, which allows for the creation of reallife-like experiences in a neuroscience laboratory setting (Bohil et al., 2011). The compatibility of VR technology with EEG recording systems allows for creating experiences with a higher degree of ecological validity and control, while recording changes in emotional brain activity. We feel that combining VR technology with EEG equipment will prove to be a fruitful avenue for studying the emotional content of experiential episodes and for optimizing experience design by systematically varying and evaluating different design options based on the emotions they elicit. 


\section{Discussion}

\section{Conclusions}

We have argued that when unpacking the experience construct into its constituent elements, rather than the predominantly cognitive elements (attention, involvement, engagement, immersion) it is the affective element of an experience - the succession of positive and negative emotions that occur during an experiential episode - that defines its memorability. Current research methods, which are mostly based on self-reports, inherently face validity issues when it comes to capturing emotions. We propose that research methods that focus on the bodily expression of emotions (facial coding, physiology, EEG), when complemented with more traditional, cognitively oriented approaches, are better geared for measuring these crucial ingredients of an experience. Furthermore, these methods have a subsecond time resolution, thus enabling researchers and managers in the field of hospitality, tourism, and leisure to evaluate the ebb and flow of emotions during an experience with fine temporal detail. Boosted by technological developments, the proposed research methods have become accessible for typical research projects in the hospitality, tourism, and leisure industries, and as a result, these methods are gradually being adopted by researchers in our field

\section{Limitations}

At the same time, the proposed research methods have their own limitations. For reasons of data quality, the use of EEG has been limited to laboratory settings, which limits its applicability in real-life experience research. Another limitation is that EEG and physiological measurements require some level of familiarity with recording procedures and quantitative signal analysis and are prone to measurement artifacts. In addition, while both EEG, HRV, and SCR capture the extent to which emotions have been engaged, these methods fail to capture precisely which emotions have been felt. Also, both SCR and HRV do not differentiate between positive and negative emotions, which can make interpretation of these findings in their own right difficult at times.

Triangulating and cross-validating the results from those measurements with each other and with facial EMG measurements or facial decoding techniques as well as with selfreport methodologies will provide a more complete and comprehensive picture of the visitor, guest, or tourist experience. Furthermore, to avoid an overly quantitative approach to experience measurement and to overcome some of the limitations of the proposed approaches, we advocate the use of qualitative research methods that allow for temporal detail (e.g., participant observation, ethnography) to complement and extend quantitative data on experiences. In any case, the application of the proposed research methodologies to experience research in the field of hospitality, tourism, and leisure is still in its infancy, and further efforts aimed at triangulating the different approaches are much needed at this point.

\section{Theoretical implications}

Experiences are the key offering in hospitality, tourism, and leisure. We have reviewed evidence that mental models stored in episodic memory serve to segment our stream of consciousness into experiential episodes. Various proposals have been made to break down experiential episodes into their constituent elements. In its broadest definition, an experience consists of sensory, cognitive, affective, behavioral, and interpersonal elements (Pearce \& Zare (2017). Crucially, we propose that affective elements (i.e., emotions) are core ingredients of such an experiential episode, as emotions are the main determinants of how an experience is evaluated and remembered. Theoretically, this implies that researchers in our field should focus more on establishing exactly how and under which conditions emotions shape experiences. Furthermore, researchers should become more aware of research methods that go 
beyond the traditional toolbox used for studying the cognitive appraisal of experiences and adopt additional methods that are more suitable for studying the temporal dynamics of emotional responses during an experience, while being aware at the same time of the methodological challenges and the limitations that these methods entail.

\section{Practical implications}

Because of their fine temporal detail, the proposed methods for studying emotions during hospitality, tourism, and leisure experiences have the potential to provide experience design professionals with a wealth of information about the strong and weak touchpoints in, for example, a check-in procedure at a hotel, a dinner at a restaurant, or a visit to a museum. This temporal detail allows for experiences to be (re)designed and optimized based on objective criteria instead of solely on personal expertise, intuition, or gut feeling. In our opinion, a bestpractice, evidence-based approach to experience management involves determining the specific emotion that a customer should feel at each touchpoint, followed by a (series of) cycle(s) involving the initial design of the experience, measuring which emotions are actually felt at which points in time, redesigning and optimizing the experience, and measuring the impact of the redesign through several iterations (see Figure 2). Such an approach is likely to give experience industry managers a clear edge over their less-informed competitors.

\section{*** Insert Figure 2 here ***}

In sum, we sketch the contours of a theoretical and methodological framework that unpacks experience into its constituent elements, with a strong emphasis on emotions as the building blocks that make experiences memorable. Applying the proposed methodologies properly involves facing new technical and conceptual challenges as well as knowing and accepting the limitations they impose on this new type of experience research. However, in our view, this new framework will greatly contribute to a deeper understanding of how visitors, tourists, and guests experience offerings in leisure, tourism, and hospitality, which in turn better enables industry partners to provide their customers with the best possible experiences. 


\section{References}

Appelhans, B.M. and Luecken, L.J. (2006), "Heart rate variability as an index of regulated emotional responding", Review of General Psychology, Vol. 10, No. 3, pp. 229-240.

Arnould E.J. and Price, L.L. (1993), "River Magic: Extraordinary Experience and the Extended Service Encounter", Journal of Consumer Research, Vol. 20, No. 1, pp. 24-45.

Baddeley, A. (2000), "The episodic buffer: a new component of working memory?", Trends in Cognitive Sciences, Vol. 4, No. 11, pp. 417-423.

Baloglu, S. and McCleary, K.W. (1999), "A model of destination image formation", Annals of Tourism Research, Vol. 26, No. 4, pp. 868-897.

Bastiaansen, M., Mazaheri, A. and Jensen, O. (2012), "Beyond ERPs: Oscillatory Neuronal Dynamics", in: Luck, S. and Kappenman, E. (Eds.) The Oxford Handbook of Event-Related Potential Components, Oxford University Press Inc., New York, NY, pp. 31-49.

Bastiaansen, M., Straatman, S., Driessen, E., Mitas, O., Stekelenburg, J. and Wang, L. (2018), "My destination in your brain: A novel neuromarketing approach for evaluating the effectiveness of destination marketing", Journal of Destination Marketing \& Management, Vol. 7, pp. 76-88.

Bastiaansen, M., Straatman, S. and Mitas, O. (2015), "Evaluating destination branding: A neuromarketing study", paper presented at the $3^{\text {rd }}$ World Research Summit for Tourism and Hospitality and $1^{\text {st }}$ USA-China Tourism Research Summit: Transforming Partnership, 15-19 December 2015, Orlando, FL.

Beedie, P. and Hudson, S. (2003), "Emergence of mountain-based adventure tourism", Annals of Tourism Research, Vol. 30, pp. 625-643.

Berntsen, D. and Rubin, D.C. (2012), Understanding Autobiographical Memory: Theories and approaches, Cambridge University Press, Cambridge, NY.

Bohil, C.J., Alicea, B. and Biocca, F.A. (2011), "Virtual reality in neuroscience research and therapy", Nature Reviews Neuroscience, Vol. 12, p. 752-762.

Bradley, M.M. and Lang, P.J. (1994), "Measuring emotion: The self-assessment manikin and the semantic differential", Journal of Behavior Therapy and Experimental Psychiatry, Vol. 25, No. 1, pp. 49-59.

Bradley, M.M. and Lang, P.J. (2000), "Measuring Emotion: Behavior, Feeling, and Physiology", in Lane, R.D. and Nadel, L. (Eds.), Cognitive Neuroscience of Emotion, Oxford University Press Inc., New York, NY, pp. 49-59.

Bradley, M.M., Miccoli, L., Escrig, M.A. and Lang, P.J. (2008), "The pupil as a measure of emotional arousal and autonomic activation", Psychophysiology, Vol. 45, pp. 602-607.

Brewer, W.F. (1987), "Schemas versus mental models in human memory", in Morris, P. (Ed.), Modelling cognition, John Wiley, Oxford, pp. 187-197.

Buszáki, G. and Draguhn, A. (2004), "Neuronal Oscillations in Cortical Networks. Science, Vol. 304, No. 5679, pp. 1926-1929.

Cabeza, R. and Nyberg, L. (2000), "Imaging Cognition II: An Empirical Review of 275 PET and fMRI Studies", Journal of Cognitive Neuroscience, Vol. 12, No. 1, pp. 1-47.

Chang, T.-Y. and Horng, S.-C. (2010), "Conceptualizing and measuring experience quality: the customer's perspective", The Service Industries Journal, Vol. 30, No. 14, pp. 2401-2419.

Clore, G. and Ketelaar, T. (1997), "Minding Our Emotions: On the Role of Automatic, Unconscious Affect", in Wyer, R.S. (Ed.), The Automaticity of Everyday Life: Advances in Social Cognition Volume X, Psychology Press, New York, NY, pp. 105-120.

Coghlan, A. and Pearce, P. (2010), "Tracking Affective Components of Satisfaction", Tourism and Hospitality Research, Vol. 10, No. 1, pp. 42-58.

Cohn, J.F., Ambadar, Z. and Ekman, P. (2007), "Observer-Based Measurement of Facial Expression With the Facial Action Coding System", in Coan, J.A. and Allen, J.J.B (Eds.), Handbook of Emotion Elicitation and Assessment, Oxford University Press Ltd., Oxford, pp. 203-221.

Cohn, M.A., Fredrickson, B.L., Brown, S.L., Mikels, J.A. and Conway, A.M. (2009), "Happiness unpacked: Positive emotions increase life satisfaction by building resilience", Emotion, Vol. 9, No. 3, pp. 361-368.

Conner, T.S. and Barrett, L.F. (2012), "Trends in Ambulatory Self-Report: The Role of Momentary Experience in Psychosomatic Medicine", Psychosomatic medicine, Vol. 74, No. 4, pp. 327337. 
Csikszentmihalyi, M. (1990), Flow: The Psychology of Optimal Experience, Harper and Row, New York, NY.

Ekman, P. (1992), “An argument for basic emotions", Cognition and Emotion, Vol. 6, No. 3-4, pp. 169-200.

Ekman, P. (1993), "Facial expression and emotion”, American psychologist, Vol. 48, No. 4, pp. 384392.

Ekman, P. and Friesen, W. (1978), Facial Action Coding System: A Technique for the Measurement of Facial Movement, Consulting Psychologists Press, Palo Alto, CA.

Ekman, P., Levenson, R.W. and Friesen, W.V. (1983), "Autonomic nervous system activity distinguishes among emotions", Science, Vol. 221, No. 4616, pp. 1208-1210.

Ermi, L. and Mäyrä, F. (2005). "Fundamental Components of the Gameplay Experience: Analyzing Immersion", in De Castell, S., and Jenson, J. (Eds.), Worlds in Play: International Perspectives on Digital Games Research, Peter Lang Publishing Inc., New York, NY, pp. 3753.

Fahrenberg, J. and Myrtek, M. (1996), Ambulatory Assessment: Computer-assisted Psychological and Psycholphysiological Methods in Monitoring and Field Studies, Hogrefe \& Huber Publishers, Göttingen.

Falk, J.H. and Dierking, L.D. (2016), The Museum Experience Revisited, Routledge, New York, NY.

Forgas, J.P. (2008), “Affect and cognition”, Perspectives on Psychological Science, Vol. 3, No. 2, pp. 94-101.

Fredrickson, B.L. (2000), "Extracting meaning from past affective experiences: The importance of peaks, ends, and specific emotions", Cognition and Emotion, Vol. 14, No. 4, pp. 577-606.

Fredrickson, B.L. and Kahneman, D. (1993), "Duration neglect in retrospective evaluations of affective episodes", Journal of Personality and Social Psychology, Vol. 65, No. 1, pp. 45-55.

Gillet, S., Schmitz, P. and Mitas, O. (2016), "The Snap-Happy Tourist: The Effects of Photographing Behavior on Tourists' Happiness", Journal of Hospitality and Tourism Research, Vol. 40, No. 1, pp. 37-57.

Hajcak, G., Weinberg, A., MacNamara, A. and Foti, D. (2012), "ERPs and the study of emotion”, in Luck, S.J. and Kappenman, E.S. (Eds.), The Oxford Handbook of Event-Related Potential Components, Oxford University Press Inc., New York, NY, pp. 441-474.

Harmon-Jones, E., Gable, P.A. and Peterson, C.K. (2010), "The role of asymmetric frontal cortical activity in emotion-related phenomena: A review and update", Biological Psychology, Vol. 84, No. 3, pp. 451-462.

Hektner, J.M., Schmidt, J.A. and Csikszentmihalyi, M. (2007), Experience Sampling Method: Measuring the Quality of Everyday Life, Sage Publications Inc., Thousand Oaks, CA.

Hosany, S., Prayag, G., Deesilatham, S., Cauševic, S. and Odeh, K. (2015), "Measuring Tourists' Emotional Experiences: Further Validation of the Destination Emotion Scale", Journal of Travel Research, Vol. 54, No. 4, pp. 482-495.

Howard, R.W. (1987), Concepts and schemata: An introduction, Cassell Educational, London.

James, W. (1912), Essays in Radical Empiricism, Longmans, Green \& Co, London.

Jantzen, C. (2013), "Experiencing and experiences: a psychological framework", Sundbo, J. and Sørensen, F. (Eds.), Handbook on the Experience Economy, Edward Elgar Publishing Ltd., Cheltenham, pp. 146-170.

Kahneman, D. (2011), Thinking, fast and slow, Farrar, Straus \& Giroux, New York, NY.

Kahneman, D., Fredrickson, B.L., Schreiber, C.A. and Redelmeier, D.A. (1993), "When More Pain is Preferred to Less: Adding a Better End", Psychological Science, Vol. 4, No. 6, pp. 401-405.

Kahneman, D. and Riis, J. (2005), "Living, and thinking about it: two perspectives on life", in Huppert, F.A., Baylis, N. and Keverne, B. (Eds.), The Science of Well-Being, Oxford University Press, Oxford, pp. 285-306.

Kim, J.-H., Ritchie, J.R.B. and McCormick, B. (2012), "Development of a Scale to Measure Memorable Tourism Experiences", Journal of Travel Research, Vol. 51, No. 1, pp. 12-25.

Kim, J. and Fesenmaier, D.R. (2015), "Measuring Emotions in Real Time: Implications for Tourism Experience Design", Journal of Travel Research, Vol. 54, No. 4, pp. 419-429.

Kirchberg, V. and Tröndle, M. (2015): The Museum Experience: Mapping the Experience of Fine Art. Curator - The Museum Journal, Vol. 58, No. 2, pp. 1-25. 
Konijn, E., Sluimer, N. and Mitas, O. (2016), "Click to Share: Patterns in Tourist Photography and Sharing", International Journal of Tourism Research, Vol. 18, No. 6, pp. 525-535.

LaBar, K.S. and Cabeza, R. (2006), "Cognitive neuroscience of emotional memory", Nature Reviews Neuroscience, Vol. 7, pp. 54-64.

Lang, P.J., Greenwald, M.K., Bradley, M.M. and Hamm, A.O. (1993), "Looking at pictures: Affective, facial, visceral, and behavioral reactions", Psychophysiology, Vol. 30, No. 3, pp. 261-273.

Larsen, R.J. and Fredrickson, B.L. (1999), "Measurement issues in emotion research", in Kahneman, D., Diener, E. \& Schwarz N. (Eds.), Well-being: The foundations of hedonic psychology, Russell Sage Foundation, New York, NY, pp. 40-60.

LeDoux, J.E. (2000), "Emotion circuits in the brain", Annual Review of Neuroscience, Vol. 23, pp. $155-184$.

Lench, H.C., Flores, S.A. and Bemch, S.W. (2011), "Discrete emotions predict changes in cognition, judgment, experience, behavior, and physiology: A meta-analysis of experimental emotion elicitations, Psychological Bulletin, Vol. 137, No. 5, pp. 834-855.

Lewinski, P., Den Uyl, T.M. and Butler, C. (2014), "Automated facial coding: Validation of basic emotions and FACS AUs in FaceReader", Journal of Neuroscience, Psychology, and Economics, Vol. 7, No. 4, pp. 227-236.

Li, J., Yang, D., He, L., Tao, S.,Zeng, L., \& Buckley, R. (2012), "Psychological, physiological and behavioural responses of tourists to interactions with rhesus macaques at Zhangjiajie, China", Journal of Ecotourism, Vol. 11, No.3, pp. 202-206.

Li, S., Scott, N., \& Walters, G. (2015), "Current and potential methods for measuring emotion in tourism experiences: a review", Current Issues in Tourism, Vol. 18, No. 9, pp. 805-827.

Li, S., Walters, G., Packer, J., \& Scott, N. (2016), "Using skin conductance and facial electromyography to measure emotional responses to tourism advertising", Current Issues in Tourism, pp. 1-23.

Li, S., Walters, G., Packer, J. \& Scott, N. (2017), "A Comparative Analysis of Self-Report and Psychophysiological Measures of Emotion in the Context of Tourism Advertising", Journal of Travel Research, pp. 1-15.

Lin, Y., Kerstetter, D., Nawijn, J. and Mitas, O. (2014), "Changes in emotions and their interactions with personality in a vacation context", Tourism Management, Vol. 40, pp. 416-424.

Luck, S.J. (2014), An Introduction to the Event-Related Potential Technique, MIT Press Ltd., Cambridge, MA.

Luck, S.J. and Kappenman, E.S. (2011), The Oxford Handbook of Event-Related Potential Components, Oxford University Press Inc., New York, NY.

Mantini, D., Perrucci, M.G., Del Gratta, C., Romani, G.L. and Corbetta, M. (2007), "Electrophysiological signatures of resting state networks in the human brain", Proceedings of the National Academy of Sciences, Vol. 104, No. 32, pp. 13170-13175.

Maslow, A.H. (1964), Religions, Values, and Peak-Experiences, Ohio State University Press, Columbus, $\mathrm{OH}$.

Matthews, R., Turner, P.J., McDonald, N.J., Ermolaev, K., McManus, T., Shelby, R.A. and Steindorf, M. (2008), "Real time workload classification from an ambulatory wireless EEG system using hybrid EEG electrodes", paper presented at the $200830^{\text {th }}$ Annual International Conference of the IEEE Engineering in Medicine and Biology Society, 20-25 August 2008, Vancouver, BC.

McAfee, A. and Brynjolfsson, E. (2012), "Big Data: The Management Revolution”, Harvard Business Review, Vol. 90, pp. 60-68.

McDuff, D., Mahmoud, A., Mavadati, M., Amr, M., Turcot, J. and El Kaliouby, R. (2016), “AFFDEX SDK: A Cross-Platform Real-Time Multi-Face Expression Recognition Toolkit", in Proceedings of the 2016 CHI Conference Extended Abstracts on Human Factors in Computing Systems, ACM, New York, NY, pp. 3723-3726.

Mehmetoglu, M. and Engen, M. (2011), "Pine and Gilmore's Concept of Experience Economy and Its Dimensions: An Empirical Examination in Tourism", Journal of Quality Assurance in Hospitality \& Tourism, Vol. 12, No. 4, pp. 237-255. 
Mihaljović, V., Grundlehner, B., Vullers, R. and Penders, J. (2015), "Wearable, Wireless EEG Solutions in Daily Life Applications: What are we Missing?", IEEE Journal of Biomedical and Health Informatics, Vol. 19, No. 1, pp. 6-21.

Mitas, O., Yarnal, C., Adams, R. and Ram, N. (2012), "Taking a "Peak" at Leisure Travelers' Positive Emotions", Leisure Sciences, Vol. 34, No. 2, pp. 115-135.

Moyle, B. D., Moyle, C.-L., Bec, A. and Scott, N. (2017), "The next frontier in tourism emotion research", Current Issues in Tourism, pp. 1-7.

Mumm, J. and Mutlu, B. (2011), "Designing motivational agents: The role of praise, social comparison, and embodiment in computer feedback", Computers in Human Behavior, Vol. 27, No. 5, pp. 1643-1650.

Nawijn, J. and Fricke, M.C. (2015), "Visitor Emotions and Behavioral Intentions: The Case of Concentration Camp Memorial Neuengamme", International Journal of Tourism Research, Vol. 17, No. 3, pp. 221-228.

Nawijn, J., Mitas, O., Lin, Y. and Kerstetter, D. (2013), "How Do We Feel on Vacation? A Closer Look at How Emotions Change over the Course of a Trip", Journal of Travel Research, Vol. 52, No. 2, pp. 265-274.

Oh, H., Fiore, A.M. and Jeoung, M. (2007), "Measuring experience economy concepts: Tourism applications", Journal of Travel Research, Vol. 46, No. 2, pp. 119-132.

Öhman, A. (1999), "Distinguishing Unconscious from Conscious Emotional Processes: Methodological Considerations and Theoretical Implications", in Dalgleish, T. and Power, M. (Eds.), Handbook of Cognition and Emotion, John Wiley \& Sons, Chichester, pp. 321-352.

Olofsson, J.K., Nordin, S., Sequiera, H. and Polich, J. (2008), "Affective picture processing: An integrative review of ERP findings", Biological Psychology, Vol. 77, No. 3, pp. 247-265.

Park, M., Oh, H. and Park, J. (2010), "Measuring the Experience Economy of Film Festival Participants", International Journal of Tourism Sciences, Vol. 10, No. 2, pp. 35-54.

Pearce, P. L., \& Zare, S. (2017), "The orchestra model as the basis for teaching tourism experience design", Journal of Hospitality and Tourism Management, Vol. 30, pp. 55-64.

Phan, K.L., Wager, T., Taylor, S.F. and Liberzon, I. (2002), "Functional Neuroanatomy of Emotion: A Meta-Analysis of Emotion Activation Studies in PET and AMRI", NeuroImage, Vol. 16, No. 2, pp. 331-348.

Pine, B.J. and Gilmore, J.H. (1998), "Welcome to the Experience Economy", Harvard Business Review, Vol. 76, pp. 97-105.

Pine, B.J. and Gilmore, J.H. (2011), The Experience Economy, rev. edn., Harvard Business Press, Boston, MA.

Popper, K.R. (1957), The Poverty of Historicism, Beacon Press, Boston, MA.

Ritchie, J.R.B., Tung, V.W.S. and Ritchie, R.J.B. (2011), "Tourism experience management research: Emergence, evolution and future directions", International Journal of Contemporary Hospitality Management, Vol. 23, No. 4, pp. 419-438.

Richins, M.L. (1997), "Measuring Emotions in the Consumption Experience", Journal of Consumer Research, Vol. 24, No. 2, pp. 127-146.

San Martín, H. and Del Bosque, I.A.R. (2008), "Exploring the cognitive-affective nature of destination image and the role of psychological factors in its formation", Tourism Management, Vol. 29, No. 2, pp. 263-277.

Scherer, K.R. (2005), "What are emotions? And how can they be measured?", Social Science Information, Vol. 44, No. 4, pp. 695-729.

Sims, R. (2009), "Food, place and authenticity: local food and the sustainable tourism experience", Journal of sustainable tourism, Vol. 17, No. 3, pp. 321-336.

Scott, N., and Le, D. (2017), "Tourism Experience: A Review”, in Scott N., Gao, J. \& Ma, J. (Eds.), Visitor Experience Design, CABI, Wallingford, pp. 30-49.

Skavronskaya, L., Scott, N., Moyle, B., Le, D., Hadinejad, A., Zhang, R., Gardiner, S., Coghlan, A. and Shakeela, A. (2017), "Cognitive psychology and tourism research: state of the art", Tourism Review, Vol. 72, No. 2, pp. 221-237.

Stone, A.A. and Shiffman, S. (1994), "Ecological momentary assessment (EMA) in behavorial medicine", Annals of Behavioral Medicine, Vol. 16, No. 3, pp. 199-202. 
Tan, S.-K., Kung, S.-F. and Luh, D.-B. (2013), “A model of 'creative experience' in creative tourism”, Annals of Tourism Research, Vol. 41, pp. 153-174.

Tonetto, L.M. and Desmet, P.M.A. (2016), "Why we love or hate our cars: A qualitative approach to the development of a quantitative user experience survey", Applied Ergonomics, Vol. 56, pp. 68-74.

Trischler, J. and Zehrer, A. (2012), "Service design: Suggesting a qualitative multistep approach for analyzing and examining theme park experiences", Journal of Vacation Marketing, Vol. 18, No. 1, pp. 57-71.

Tröndle, M. \& Tschacher, W. (2012), "The Physiology of Phenomenology: The Effects of Artworks", Journal of Empirical Studies of the Arts, Vol. 30, No. 1, pp. 79-117.

Tröndle, M., Greenwood, S., Kirchberg, V. \& Tschacher, W. (2014a), "An Integrative and Comprehensive Methodology for Studying Aesthetic Experience in the Field: Merging Movement Tracking, Physiology and Psychological Data", Environment and Behavior, Vol. 46, No. 1, pp. 102-135.

Tröndle, M., Kirchberg, V., \& Tschacher, W. (2014b), "Subtle Differences: Men, Women and their Art Reception", The Journal of Aesthetic Education, Vol. 48, No. 4, pp. 65-93.

Tsaur, S.-H., Yen, C.-H. and Hsiao, S.-L. (2013), "Transcendent Experience, Flow and Happiness for Mountain Climbers", International Journal of Tourism Research, Vol. 15, No. 4, pp. 360-374.

Tschacher, W., Greenwood, S., Kirchberg, V., Wintzerith, S., van den Berg, K., \& Tröndle, M. (2012), "Physiological correlates of aesthetic perception in a museum", Psychology of Aesthetics, Creativity, and the Arts, Vol. 6, No. 1, pp. 96-103.

Tulving, E. (1989), "Memory: Performance, knowledge, and experience", European Journal of Cognitive Psychology, Vol. 1, No. 1, pp. 3-26.

Van Schaik, P.V. and Ling, J. (2012), "An Experimental Analysis of Experiential and Cognitive Variables in Web Navigation", Human-Computer Interaction, Vol. 27, No. 3, pp. 199-234.

Varela, F., Lachaux, J.-P., Rodriguez, E. and Martinerie, J. (2001), "The brainweb: Phase synchronization and large-scale integration", Nature Reviews Neuroscience, Vol. 2, No. 4, pp. 229-39.

Winkielman, P. and Berridge, K.C. (2004), "Unconscious Emotion", Current Directions in Psychological Science, Vol. 13, No. 3, pp. 120-123.

Yazicioglu, R.F., Merken, P., Puers, R. and Van Hoof, C. (2008), "A 200 $\mu$ W Eight-Channel EEG Acquisition ASIC for Ambulatory EEG Systems", IEEE Journal of Solid-State Circuits, Vol. 43, No. 12, pp. 3025-3038.

Zajchowski, C.A., Schwab, K.A. and Dustin, D.L. (2017), "The Experiencing Self and the Remembering Self: Implications for Leisure Science", Leisure Sciences, Vol. 39, No. 6, pp. 561-568. 